\title{
Management of psoriatic lesions associated with anti-TNF therapy in patients with IBD
}

Rafael Denadai, Fábio V. Teixeira and Rogério Saad-Hossne

We read with great interest the Review by Cleynen and Vermeire (Paradoxical inflammation induced by anti-TNF agents in patients with IBD. Nat. Rev. Gastroenterol. Hepatol. 9, 496-503 [2012]). ${ }^{1}$ As described by the authors, the outcomes of psoriatic lesions induced or exacerbated by anti-TNF agents are variable. Given that most of the evidence concerning this cutaneous reaction has been obtained from the rheumatological literature, ${ }^{2-4}$ disagreement exists as to the need to suspend anti-TNF therapy to achieve complete resolution of these lesions in patients with IBD. Some studies ${ }^{5,6}$ (cited by Cleynen and Vermeire) report that the biologic agent should be maintained. On the other hand, the largest study ${ }^{4}$ available on this topic reported that discontinuing anti-TNF therapy has been particularly successful in patients with IBD. However, these data must be interpreted with caution because anti-TNF withdrawal can worsen or reactivate symptoms of IBD. Furthermore, a limited number of patients with IBD were evaluated in these studies. ${ }^{4-6}$ In this context, our group have conducted three systematic reviews to collect information on this paradoxical phenomenon specifically in patients with IBD. ${ }^{7-9}$ To the best of our knowledge, the latest review ${ }^{9}$ contains the largest number of patients with IBD and anti-TNF-related psoriatic lesions to date $(n=222)$. In this study, ${ }^{9}$ we included data from 47 publications, including most of the cohort studies ${ }^{5,6,10}$ cited by the authors. Analysis of this data set demonstrated that patients with IBD who develop psoriatic lesions should be treated using a standard antipsoriatic therapy (for example, topical corticosteroids, emollients or keratolytic therapy) without discontinuing or switching their anti-TNF agent. ${ }^{9}$ Discontinuation of anti-TNF therapy should be reserved for patients with lesions covering $>5 \%$ of their body surface area or with lesions refractory to therapy, and when quality of life is severely impaired. ${ }^{9}$ Physicians who deal with these patients should know this data to provide specific management.

Division of Coloproctology, Department of Surgery, School of Medical Sciences, University of the State of São Paulo (UNESP), Paula Fabiana Tudela, 161 - Esmeralda 17516-707, Marília, São Paulo, Brazil (R. Denadai, F. V. Teixeira, R. Saad-Hossne).

Correspondence to: $R$. Denadai denadai.rafael@hotmail.com

doi:10.1038/nrgastro.2012.125-c1

Competing interests

The authors declare no competing interests.

1. Cleynen, I. \& Vermeire, S. Paradoxical inflammation induced by anti-TNF agents in patients with IBD. Nat. Rev. Gastroenterol. Hepatol. 9, 496-503 (2012).

2. Lee, H. H. et al. Cutaneous side-effects in patients with rheumatic diseases during application of tumour necrosis factor- $\alpha$ antagonists. Br. J. Dermatol. 156, 486-491 (2007).
3. Harrison, M. J. et al. Rates of new-onset psoriasis in patients with rheumatoid arthritis receiving anti-tumour necrosis factor a therapy: results from the British Society for Rheumatology Biologics Register. Ann. Rheum. Dis. 68, 209-215 (2009).

4. Collamer, A. N. \& Battafarano, D. F. Psoriatic skin lesions induced by tumor necrosis factor antagonist therapy: clinical features and possible immunopathogenesis. Semin. Arthritis Rheum. 40, 233-240, (2010).

5. Rahier, J. F. et al. Severe skin lesions cause patients with inflammatory bowel disease to discontinue anti-tumor necrosis factor therapy. Clin. Gastroenterol. Hepatol. 8, 1048-1055 (2010).

6. Baumgart, D. C., Grittner, U., Steingraber, A., Azzaro, M. \& Philipp, S. Frequency, phenotype, outcome, and therapeutic impact of skin reactions following initiation of adalimumab therapy: experience from a consecutive cohort of inflammatory bowel disease patients. Inflamm. Bowel Dis. 17, 2512-2520 (2011).

7. Steinwurz, F. et al. Infliximab-induced psoriasis during therapy for Crohn's disease. J. Crohns Colitis. 6, 610-616 (2012).

8. Denadai, R., Teixeira, F. V. \& Saad-Hossne, R. The onset of psoriasis during the treatment of inflammatory bowel diseases with infliximab: should biological therapy be suspended? Arq. Gastroenterol. 49, 172-176 (2012).

9. Denadai, R., Teixeira, F. V., Steinwurz, F., Romiti, R. \& Saad-Hossne, R. Induction or exacerbation of psoriatic lesions during anti-TNF- $\alpha$ therapy for inflammatory bowel disease: A systematic literature review based on 222 cases. J. Crohns Colitis http:// dx.doi.org/10.1016/j.crohns.2012.08.007.

10. Cullen, G., Kroshinsky, D., Cheifetz, A. S. \& Korzenik, J. R. Psoriasis associated with antitumour necrosis factor therapy in inflammatory bowel disease: a new series and a review of 120 cases from the literature. Aliment. Pharmacol. Ther. 34, 1318-1327 (2011). 